\section{Irrigation Water Quality and Trinexapac-ethyl Effects on Bermudagrass Response to Deficit Irrigation}

\author{
Reagan W. Hejl \\ RiceTec, Inc., Alvin, TX 77511 \\ Benjamin G. Wherley, James C. Thomas ${ }^{1}$, and Richard H. White
Department of Soil and Crop Science, Texas A\&M University, College
Station, TX 77843
}

Additional index words. evapotranspiration, growth regulator, salinity, sodium, Tifway, drought stress

\begin{abstract}
As the need for landscape and golf course water conservation increases, use of low-quality irrigation water combined with deficit irrigation practices is becoming more common. Information is lacking concerning the effects of water quality on bermudagrass response to deficit irrigation, as well as the extent to which plant growth regulators may ameliorate or delay the negative effects of water stress on warm-season turfgrass. The objectives of this 10-week greenhouse study were to 1) characterize growth, quality, and evapotranspiration (ET) of 'Tifway' bermudagrass (Cynodon dactylon $\times$ C. traansvalensis Burt Davy) when irrigated at full $\left(1.0 \times \mathrm{ET}_{\mathrm{a}}\right)$ or deficit $\left(0.3 \times \mathrm{ET}_{\mathrm{a}}\right)$ levels of actual turfgrass evapotranspiration $\left(\mathrm{ET}_{\mathrm{a}}\right)$ using three irrigation water sources [reverse osmosis (RO), sodic potable, and saline] and 2) determine whether application of trinexapac-ethyl (TE) could mitigate turfgrass quality decline under deficit irrigation. Results indicated that turf irrigated with sodic irrigation water exhibited significantly elevated $\mathbf{E T}_{\mathrm{a}}$ and shoot growth compared with turf receiving $\mathrm{RO}$ or saline irrigation water in both studies. Irrigation water source affected turfgrass quality differently at each irrigation level. TE application improved turfgrass quality and/or delayed firing under soil moisture stress in both studies, with the greatest benefit noted under the less intense conditions of the spring experiment. Elevated canopy temperatures were observed within all deficit irrigation treatments, regardless of water chemistry. Results demonstrate that irrigation water quality may influence turfgrass ET rates. In addition, they suggest that trinexapac-ethyl may offer short-term mitigation of drought stress under deficit irrigation.
\end{abstract}

One means of achieving water conservation in turf management is by providing water at rates below a plant's maximal consumptive water use, otherwise known as deficit irrigation (Feldhake et al., 1984; Fry and Butler, 1989; Qian and Engelke, 1999). Relative to their cool-season counterparts, warm-season turfgrasses are well adapted for deficit irrigation practices, largely due to their superior water-use efficiency and tolerance of heat and drought (Brown and Kopec, 2000; Fu et al., 2004).

Bermudagrass (Cynodon ssp.) is a widely used warm-season turfgrass species that has shown the capacity to maintain acceptable appearance at deficit irrigation levels $(\mathrm{Fu}$ et al., 2004; Wherley et al., 2014). However, little is known concerning how irrigation water quality may affect the extent of deficit irrigation tolerable by turfgrass. This has

Received for publication 3 Apr. 2015. Accepted for publication 21 May 2015.

This research was supported in part by Texas A\&M AgriLife Research.

${ }^{1}$ To whom reprint requests should be addressed; e-mail b-wherley@tamu.edu. noted that sodium-related water quality issues including elevated sodium absorption ratios (SAR) and sodium carbonates were primary concerns with their water (Throssell et al., 2009). Asano et al. (1984) reported on effluent water-quality parameters for multiple wastewater treatment plants in California and noted that $\mathrm{Na}$ content of the sources generally ranged from 109 to $186 \mathrm{ppm}$ and SAR ranged from 3.3 to 5.7. Information concerning direct effects of sodic irrigation water on turfgrass growth and water use is lacking.

As water availability for turfgrass irrigation becomes more limited, it is also of practical interest to explore products capable of reducing water consumption and/or improving turfgrass quality under drought stress. Plant growth regulators such as TE [4-(cyclopropyl-a-hydroxymethylene)-3,5dioxo-cyclohexanecarboxylic acid, ethyl ester] reduce turfgrass shoot growth by inhibiting the biologically active forms of gibberellins (King et al., 1997; Turgeon, 2002). Application of TE has been reported to improve heat and drought tolerance of coolseason turf species perennial ryegrass (Lolium perenne L.) and creeping bentgrass (Agrostis stolonifera L.) (Jiang and Fry, 1998; McCann and Huang, 2007). However, in the previously mentioned study with bentgrass, TE was applied several weeks before the onset of drought conditions. Since, turfgrasses generally metabolize TE within 2 to 6 weeks (Kreuser and Soldat, 2011), the benefits of applying TE to enhance tolerance to water stress could potentially be improved through repeat applications made both before and during progressive water stress. Information is lacking concerning the effects of TE on tolerance of warm-season turfgrasses to deficit irrigation and drought conditions.

The objectives of this 10-week greenhouse study were to 1) characterize growth, quality, and ET of 'Tifway' bermudagrass (Cynodon dactylon $\times$ C. transvaalensis Burt Davy) when irrigated at full $\left(1.0 \times \mathrm{ET}_{\mathrm{a}}\right)$ or deficit $\left(0.3 \times \mathrm{ET}_{\mathrm{a}}\right)$ irrigation levels using three irrigation water sources (RO, sodic, and saline) and 2) determine whether application of TE could mitigate turfgrass quality decline under deficit irrigation.

U.S. regions surveyed.

Nonpotable water sources often contain high levels of sodium that may cause plantrelated problems, soil related problems, or both. For example, saline water sources often contain high levels of sodium chloride causing direct osmotic injury to turf shoots, roots, or both. Salinity stress ultimately renders the plant unable to absorb water present in the soil (Marcum, 2006; McFarland et al., 2002). Another common problem associated with low-quality irrigation water is the presence of sodium bicarbonate, which can cause rapid deterioration of soil structure due to dispersion of soil colloids (Marcum, 2006). Golf courses in regions of the United States with greater dependence on recycled water also

\section{Materials and Methods}

This research was conducted in a glasshouse at Texas A\&M University, College Station, TX. The 10-week experiment was started on 6 Mar. 2013 (hereafter referred as "spring study") and repeated beginning on 17 June 2013 (hereafter referred as "summer study"). Greenhouse temperatures were set to $30 / 23{ }^{\circ} \mathrm{C}$ (day/night) for both studies. Six weeks before each study, $10.2 \mathrm{~cm}$ diameter washed sod plugs of 'Tifway' bermudagrass (Cynodon dactylon $\times$ C. transvaalensis Burt Davy) were established in 36 lysimeters constructed from polyvinyl chloride pipe (30.5 cm height $\times 81 \mathrm{~cm}^{2}$ diameter). Lysimeters were filled with a medium-textured, washed sand amended with complete starter 
Table 1. Water-quality parameters for the three water-source treatments used in the greenhouse studies, along with their respective United States Salinity Laboratory (USSL) classifications.

\begin{tabular}{lllllcrrrr}
\hline & $\begin{array}{c}\text { USSL } \\
\text { classification }\end{array}$ & $\begin{array}{c}\text { Na } \\
\text { hazard }\end{array}$ & $\begin{array}{c}\text { Salinity } \\
\text { hazard }\end{array}$ & $\mathrm{pH}$ & $\begin{array}{c}\text { Electrical } \\
\text { conductivity } \\
\left(\mathrm{dS} \cdot \mathrm{m}^{-1}\right)\end{array}$ & $\begin{array}{c}\text { Bicarbonate } \\
(\mathrm{ppm})\end{array}$ & $\mathrm{Na}(\mathrm{ppm})$ & $\begin{array}{r}\text { Sodium absorption } \\
\mathrm{Cl}(\mathrm{ppm})\end{array}$ \\
\hline $\begin{array}{l}\text { Reverse } \\
\text { osmosis }\end{array}$ & C1-S1 & Low & Low & 5.9 & 0 & 0 & $<1$ & $<1$ \\
Saline & C3-S4 & High & High & 6.6 & 7.5 & 0 & 1,972 & 3,030 \\
Sodic potable & C1-S4 & High & Low & 8.4 & $<1$ & 509 & 234 & 8.1 \\
\hline
\end{tabular}

Table 2. Analysis of variance table for date, irrigation source, level, and trinexapac-ethyl (TE) effects on various parameters during spring and summer studies. Study main effect was significant for each parameter $(P \leq 0.05)$

\begin{tabular}{|c|c|c|c|c|c|c|c|c|}
\hline & \multicolumn{8}{|c|}{$P$ values } \\
\hline & \multicolumn{2}{|c|}{ Evapotranspiration } & \multicolumn{2}{|c|}{ Visual quality } & \multicolumn{2}{|c|}{ Clipping dry wt } & \multicolumn{2}{|c|}{ Canopy temperatures } \\
\hline & Study 1 & Study 2 & Study 1 & Study 2 & Study 1 & Study 2 & Study 1 & Study 2 \\
\hline$\overline{\text { Date (D) }}$ & $* * *$ & $* * *$ & $* * *$ & $* * *$ & $* * *$ & $* * *$ & $* * *$ & $* * *$ \\
\hline Source (S) & $* * *$ & $* * *$ & $* * *$ & $* * *$ & NS & $* * *$ & $* * *$ & $* * *$ \\
\hline Level (L) & - & - & $* * *$ & $* * *$ & NS & $* * *$ & $* * *$ & $* * *$ \\
\hline $\mathrm{TE}$ & - & - & $* * *$ & $* * *$ & $* *$ & $* * *$ & $* *$ & NS \\
\hline $\mathrm{D} \times \mathrm{S}$ & NS & NS & $* * *$ & NS & $* * *$ & $* * *$ & $* * *$ & $* * *$ \\
\hline $\mathrm{D} \times \mathrm{L}$ & - & - & $* * *$ & $* * *$ & NS & $* * *$ & $* * *$ & $* * *$ \\
\hline $\mathrm{D} \times \mathrm{TE}$ & - & - & $* * *$ & NS & $* * *$ & $* * *$ & $* * *$ & NS \\
\hline $\mathrm{S} \times \mathrm{L}$ & - & - & $* * *$ & $* * *$ & NS & $* * *$ & $* * *$ & $* * *$ \\
\hline $\mathrm{S} \times \mathrm{TE}$ & - & - & $* * *$ & NS & NS & $* * *$ & NS & NS \\
\hline $\mathrm{L} \times \mathrm{TE}$ & - & - & $* * *$ & NS & NS & NS & NS & NS \\
\hline $\mathrm{D} \times \mathrm{S} \times \mathrm{L}$ & - & - & $* * *$ & NS & NS & $* * *$ & $*$ & $* *$ \\
\hline $\mathrm{D} \times \mathrm{S} \times \mathrm{TE}$ & - & - & $* *$ & NS & NS & $* * *$ & NS & $*$ \\
\hline $\mathrm{D} \times \mathrm{L} \times \mathrm{TE}$ & - & - & $* *$ & NS & NS & $* * *$ & NS & NS \\
\hline $\mathrm{S} \times \mathrm{L} \times \mathrm{TE}$ & - & - & NS & NS & NS & $* * *$ & NS & NS \\
\hline$\underline{\mathrm{D} \times \mathrm{S} \times \mathrm{L} \times \mathrm{TE}}$ & 一 & 一 & NS & NS & NS & $* * *$ & NS & NS \\
\hline
\end{tabular}

NS, $* * *, * *$ Nonsignificant or significant at $P=0.05,0.01$, or 0.001 , respectively.

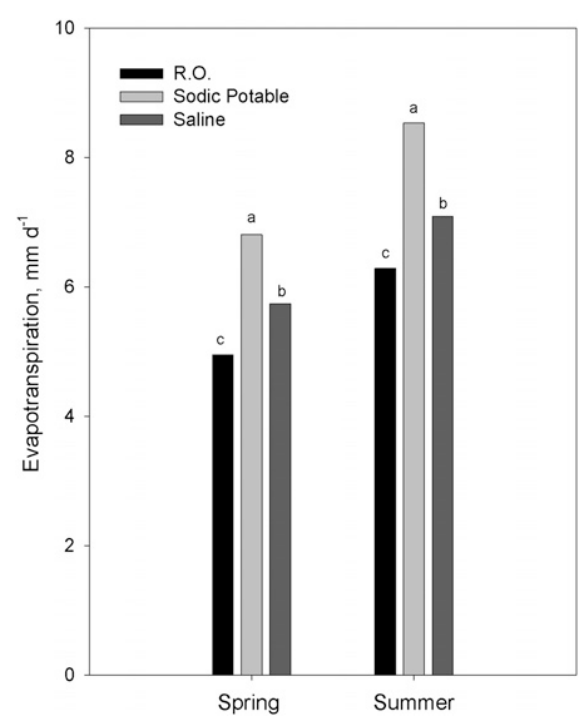

Fig. 1. Daily evapotranspiration $\left(\mathrm{ET}_{\mathrm{a}}\right)$ of fully irrigated treatments. Bars with the same letter within a given study are not significantly different based on Tukey's honestly significant difference at $P \leq 0.05$.

fertilizer (21-7-14) containing sulfur-coated urea (BCF Products, Greenville, TX) applied at a rate of $4.9 \mathrm{~g} \mathrm{~N} / \mathrm{m}^{2}$ as well as micronutrients (Step Hi-Mag, Andersons, Inc., Maumee, OH).

The study was a completely randomized design with three replications. A factorial treatment arrangement with of all possible combinations of two irrigation levels, three water sources, and two TE levels was used.
TE was applied at a rate of either 0 or $28 \mathrm{mg}$ a.i. $/ \mathrm{m}^{2}$, with applications made at the start of weeks 1, 4, and 7 using a $\mathrm{CO}_{2}$ powered backpack sprayer with XR Teejet 8002 VS nozzles (Spraying System Co., Wheaton, IL) at $40 \mathrm{psi}$ and calibrated to deliver a carrier volume of $81.5 \mathrm{~mL} \mathrm{H}_{2} \mathrm{O} / \mathrm{m}^{2}$. Water source treatments included 1) RO (generated through a greenhouse RO unit), 2) sodic potable (the local potable water which poses a potential $\mathrm{Na}$, but not salinity hazard), and 3 ) saline [produced by mixing $4.8 \mathrm{~g}$ of $\mathrm{NaCl}$ per liter of RO water resulting in a final electrical conductivity (EC) of $7.5 \mathrm{dS} \cdot \mathrm{m}^{-1}$ ]. Pertinent water chemistry parameters for each of the waters are summarized in Table 1.

Immediately before beginning the experiment, all lysimeters were brought to field capacity by fully submerging in RO water until air bubbles had ceased, indicating saturation had been reached $(\approx 1$ min submersion). Lysimeters were then allowed to drain freely for $18 \mathrm{~h}$, at which time drainage was no longer detected. These starting field capacity masses for the lysimeters were then measured and recorded for future reference during weighing and irrigation events. All lysimeters were irrigated twice weekly during the study period. Irrigation levels included full ET replacement $[1.0 \times$ actual evapotranspiration $\left.\left(\mathrm{ET}_{\mathrm{a}}\right)\right]$ and deficit irrigation $(0.3 \times$ $\mathrm{ET}_{\mathrm{a}}$ ).

$\mathrm{ET}_{\mathrm{a}}$ was determined by weighing and calculating the mean mass change of three fully watered $\left(1.0 \times \mathrm{ET}_{\mathrm{a}}\right)$ lysimeters within each of the three water source treatments. Irrigation was then supplied at either full

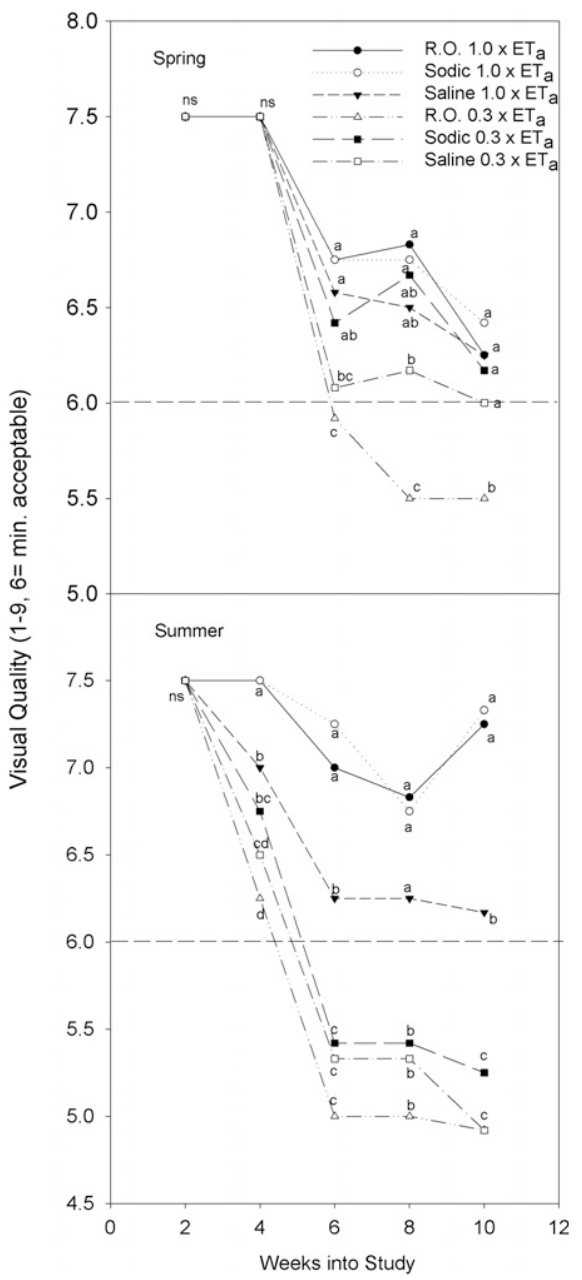

Fig. 2. Visual turf quality for both studies as affected by water source and irrigation level. Data are pooled across trinexapac-ethyl (TE) applications. Means with the same letter on a given date and study are not significantly different based on Fishers least significant difference at $P \leq 0.05$. Dashed horizontal line denotes minimum acceptable quality.

$\left(1.0 \times \mathrm{ET}_{\mathrm{a}}\right)$ or deficit $\left(0.3 \times \mathrm{ET}_{\mathrm{a}}\right)$ replacement levels during the 10 -week study period, similar to that described by Wherley (2011). As such, within each water source, treatments receiving TE received the same irrigation volumes as their non-TE-treated counterparts throughout the study.

Turfgrass visual quality was evaluated during the study through biweekly visual assessments (rating scale of 1-9, minimal acceptable rating $=6$ ). These quality ratings took into account color, density, and uniformity of the turf canopy; although quality 


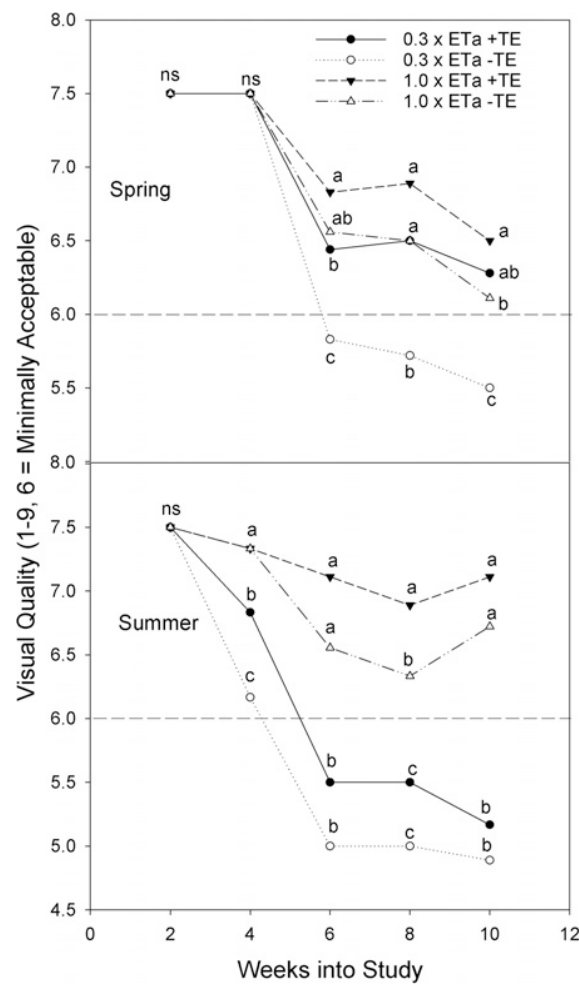

Fig. 3. Visual turf quality for both studies as affected by trinexapac-ethyl (TE) application and irrigation level. Data were pooled across water sources. Means with the same letter on a given date and study are not significantly different based on Fishers least significant difference at $P \leq 0.05$. Dashed horizontal line denotes minimum acceptable quality.

differences noted in the study were primarily attributable to changes in color due to leaf firing. A rating of 1 indicated completely fired leaf canopy and a rating of 9 represented fully dense, dark green, perfectly uniform turf.

Growth was measured through regular collection of clippings. Turfgrass within each lysimeter was trimmed to $1.9 \mathrm{~cm}$ at $7-$ to $10-\mathrm{d}$ intervals during the study using scissors and ruler. Clippings were collected, oven dried for $72 \mathrm{~h}$ at $65{ }^{\circ} \mathrm{C}$, and weighed. For each period, clipping dry weights were divided by the number of growing days to calculate daily growth rate for each column.

Soil salinity levels were measured at the $7.6 \mathrm{~cm}$ depth within lysimeters at the middle (week 5) and end (week 10) of the study using an EC probe (Spectrum Technologies, Aurora, IL). Canopy temperature readings were also recorded on a biweekly basis during cloudless afternoon periods using a handheld infrared thermometer (Model 2956; Spectrum Technologies) as an early physiological indicator of potential drought or salinity stress. A single reading was taken at the center of the turf canopy.

Data for all parameters were subjected to analysis of variance (ANOVA) using the general linear model, univariate test procedure using SPSS ver. 21.0 (IBM Corp, Armonk, NY) to determine statistical significance

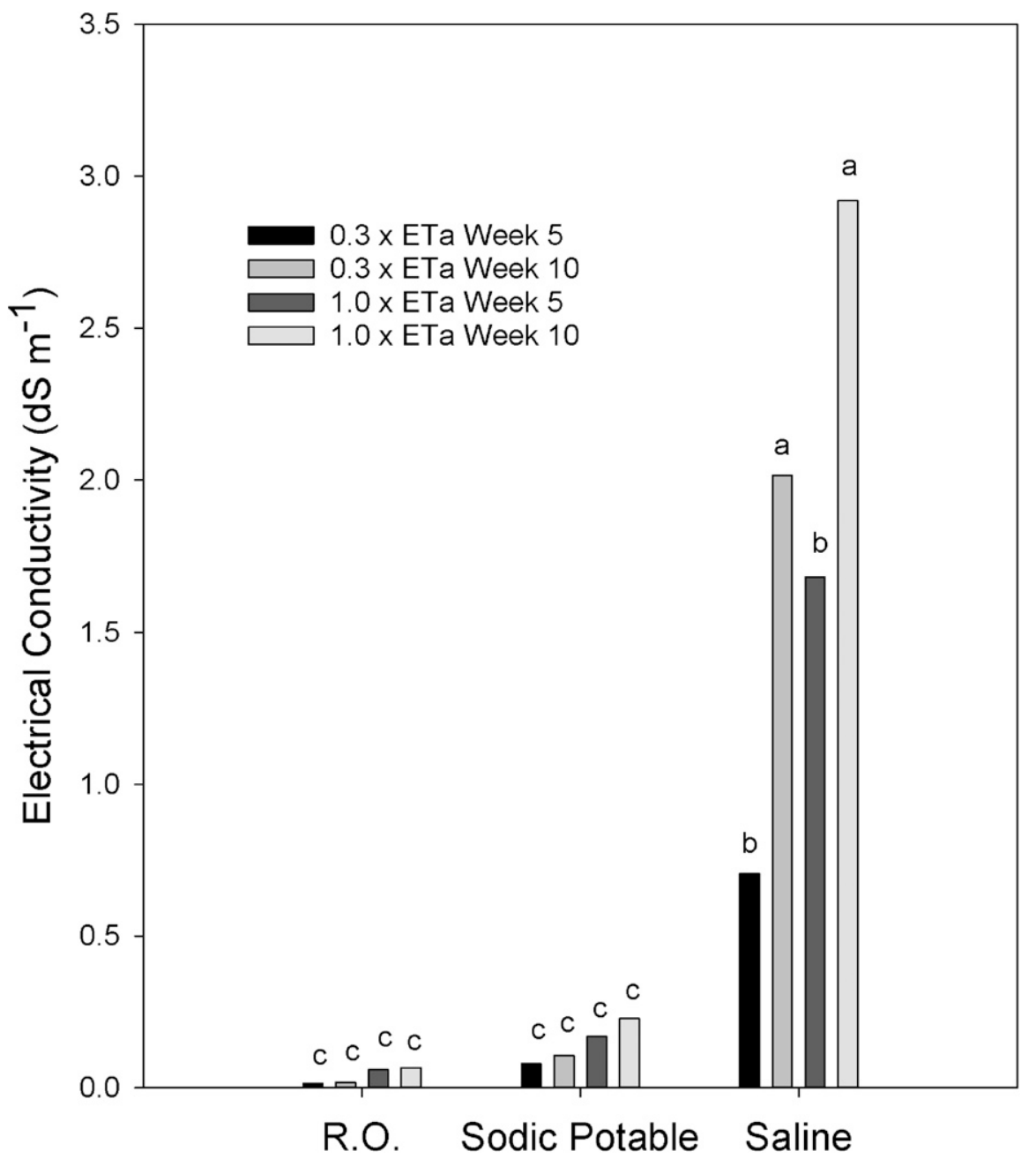

Fig. 4. Electrical conductivity at weeks 5 and 10 as affected by water source and irrigation level. Means were averaged across both studies. Means with the same letter on a given week and water source are not significantly different based on Fishers least significant difference at $P \leq 0.05$.

of the results. Where ANOVA indicated a significant study effect, parameters were presented separately by study. Mean separation procedures were performed using Tukey's honestly significant difference at the $P \leq 0.05$ level.

\section{Results and Discussion}

Effects of irrigation source on ET rates. Irrigation source had a significant effect on $\mathrm{ET}_{\mathrm{a}}$ in both studies (Table 2). As such, turf receiving sodic potable irrigation water exhibited significantly higher daily $\mathrm{ET}_{\mathrm{a}}$ relative to RO and saline irrigation treatments (Fig. 1). There was also a significant main effect of measurement date on ET, with $\mathrm{ET}_{\mathrm{a}}$ generally increasing as the experiment progressed toward summer due to longer days and more intense solar radiation (data not shown). In the spring study, turf receiving RO exhibited the lowest water use $\left(4.9 \mathrm{~mm} \cdot \mathrm{d}^{-1}\right)$, saline-irrigated turf had an intermediate water use $\left(5.7 \mathrm{~mm} \cdot \mathrm{d}^{-1}\right)$, and turf irrigated with sodic potable water had the greatest water use $\left(6.8 \mathrm{~mm} \cdot \mathrm{d}^{-1}\right)$. Similarly, in the summer study, water use rates were $6.3,7.1$, and $8.5 \mathrm{~mm} \cdot \mathrm{d}^{-1}$ for plants irrigated with $\mathrm{RO}$, saline, and sodic potable water, respectively. The relative differences in water use rates among treatments were fairly consistent across both studies with $\mathrm{ET}_{\mathrm{a}}$ rates of sodic-irrigated turf occurring at $\approx 2 \mathrm{~mm} \cdot \mathrm{d}^{-1}$ greater than the $\mathrm{RO}$ treatment $(35 \%$ and $39 \%$ greater than $\mathrm{RO}$ for the spring and summer studies, respectively), and $\approx 1.1 \mathrm{~mm} \cdot \mathrm{d}^{-1}$ greater than the saline treatment. The overall greater $\mathrm{ET}_{\mathrm{a}}$ rates in summer were most likely due to longer days and higher levels of incident radiation levels in the greenhouse during the summer months (data not shown). While ET rates of 2 to $5 \mathrm{~mm} \cdot \mathrm{d}^{-1}$ are commonly reported for warm-season turfgrasses, rates approaching $10 \mathrm{~mm} \cdot \mathrm{d}^{-1}$ are also not uncommon under high evaporative demand conditions (Duble, 2006; Huang and Fry, 1999).

Previous research investigating turfgrass or plant ET rates in response to irrigation chemistry factors has been limited; however, the majority of studies have focused on salinity effects. While salinity is not typically adjusted for when determining reference-ETbased irrigation requirements, it presumably could result in overestimation of ET due to 


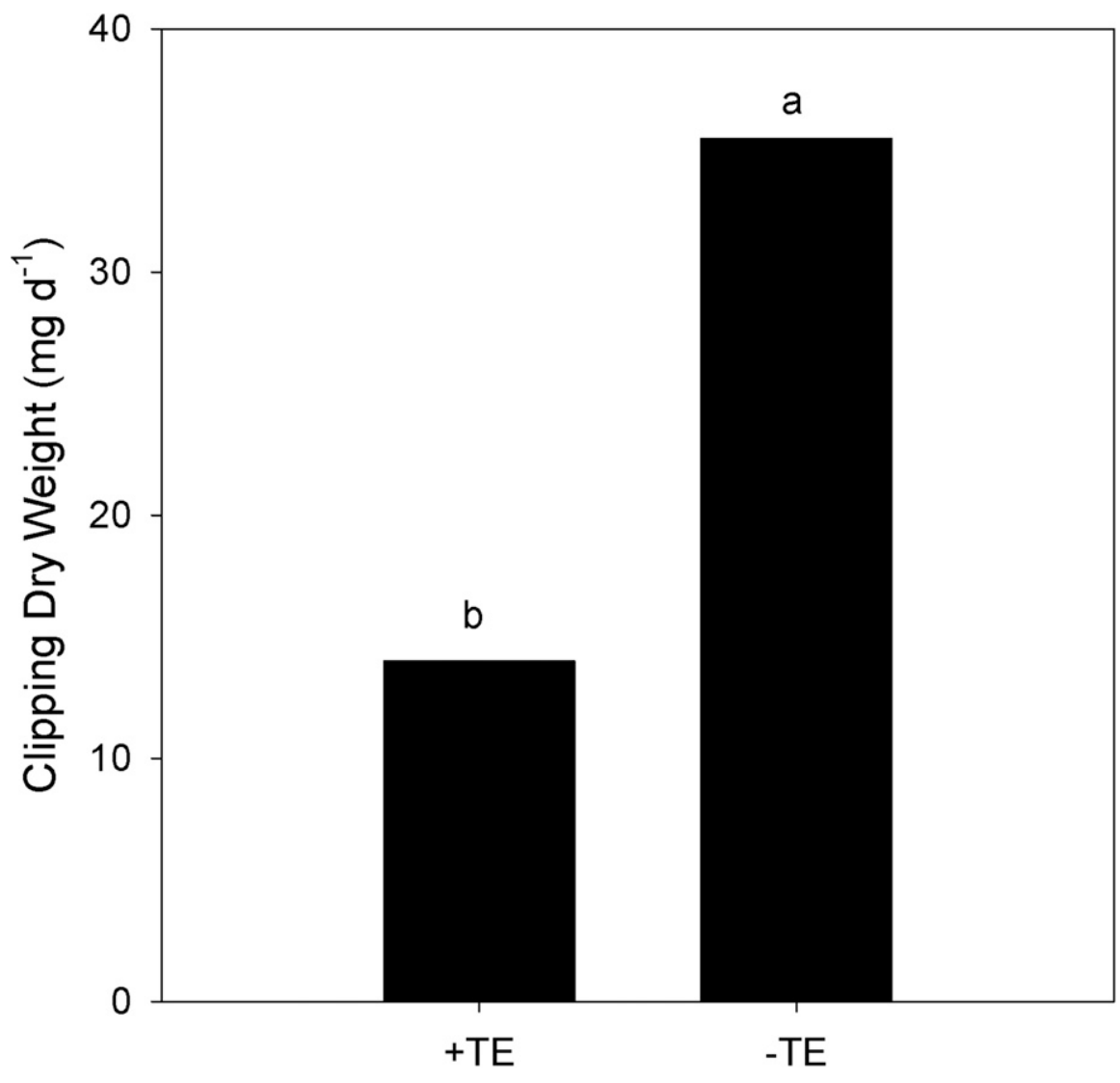

Fig. 5. Grass clipping dry weight from Study 1 as affected by trinexapac-ethyl (TE). Data were pooled across all irrigation levels and water sources. Bars with the same letter are not significantly different based on Tukey's honestly significant difference at $P \leq 0.05$.

osmotic effects on water uptake and reduced plant transpiration (Ben-Gal et al., 2008; Bernstein, 1975). The observation that water quality, particularly the sodic irrigation, considerably affected ET rates in this study has notable practical significance in terms of reference-ET-based irrigation scheduling practices. While it will be important to further validate these findings under field conditions, the results suggest that to effectively meet plant demand, turf managers applying high-Na irrigation on the basis of reference ET would need to compensate for increased ET rates through increased irrigation volumes. We can only speculate as to the mechanistic basis for this response; however, elevated $\mathrm{pH}$, sodium, bicarbonate, or other possible factors unique to this municipal water source deserve further investigation. A review of the literature indicates little to no information relating to the influence of $\mathrm{pH}$ or sodium on plant transpiration. Some past work has explored effects of root zone carbonate and bicarbonate on growth of multiple crop species (Alhendawi et al., 2008; Pierce et al., 1999; Stolwijk and Thimann,1957), but effects have been found to be largely negative in nature, and therefore would not be consistent with the observed elevated ET rates. Increased rates of growth and ET because of elevated $\mathrm{Na}$ from the municipal irrigation would therefore seem most plausible. While not typically quality ratings declined slightly across all $1.0 \times \mathrm{ET}_{\mathrm{a}}$ irrigation treatments during both studies, possibly due to gradual depletion of the initial $\mathrm{N}$ fertilizer application and periodic removal of clippings during the study.

Within the deficit irrigation treatments, saline- and sodic-irrigated treatments maintained at or above acceptable levels of quality throughout the spring study; however, ROirrigated turf decreased to below-acceptable quality levels beginning at week 6 of the spring study (Fig. 2). The significantly lower quality observed within deficit-irrigated RO plants was likely a response to the lower volumes of irrigation received relative to sodic- and saline-irrigated treatments. Because $\mathrm{ET}_{\mathrm{a}}$ of fully irrigated RO-treated plants was somewhat lower than other water sources, proportionally lower volumes of water were necessarily applied within the corresponding RO deficit-irrigated treatments, based on our methodology employed.

During study 2, longer summer days and more intense radiation prevailed, resulting in somewhat higher levels of stress in the deficit-irrigated treatments. Significant differences in visual quality occurred among water sources at both the 1.0 and $0.3 \times \mathrm{ET}_{\mathrm{a}}$ levels (Fig. 2). At the $1.0 \times \mathrm{ET}_{\mathrm{a}}$ irrigation level, saline irrigation resulted in significant reductions in visual quality relative to both $\mathrm{RO}$ and sodic water on three of the five rating dates. Under deficit $\left(0.3 \times \mathrm{ET}_{\mathrm{a}}\right)$ irrigation, there were no differences in quality because of water sources, and all treatment means fell to below the minimal acceptable quality of six between weeks 4 and 6 (Fig. 2).

There was also a significant date $\times$ irrigation level $\times$ TE interaction on visual quality during the spring study, as well as a significant main effect of TE on visual quality in both studies (Table 2). As such, TE application noticeably influenced visual quality in the deficit stress irrigation $\left(0.3 \times \mathrm{ET}_{\mathrm{a}}\right)$ treatment during spring, and showed positive benefit under both irrigation levels during the summer study (Fig. 3). During the spring study, application of TE led to delayed leaf firing and sustained acceptable turf quality levels $(\geq 6)$ under deficit irrigation during all weeks, while turf quality decreased to belowacceptable quality after week 6 in the absence of TE (Fig. 3). In the summer study, although TE provided a slight increase in quality at both irrigation levels, both TE and non-TEtreated plants had declined to belowacceptable quality levels by week 6 under deficit irrigation (Fig. 3).

A date $\times$ irrigation source $\times$ TE interaction on visual quality was also noted for the spring study (Table 2). As such, no statistical differences were detected between water source $x$ TE treatments at week 2, with all treatments averaging a rating of 7.5 for visual quality. However, as the study progressed, visual quality declined in some treatments to a greater extent than others. For example, "sodic potable +TE" maintained the highest quality during the study, ending with a final rating of 7, whereas "RO-TE" treated plants declined to a quality of 5.58 by the 


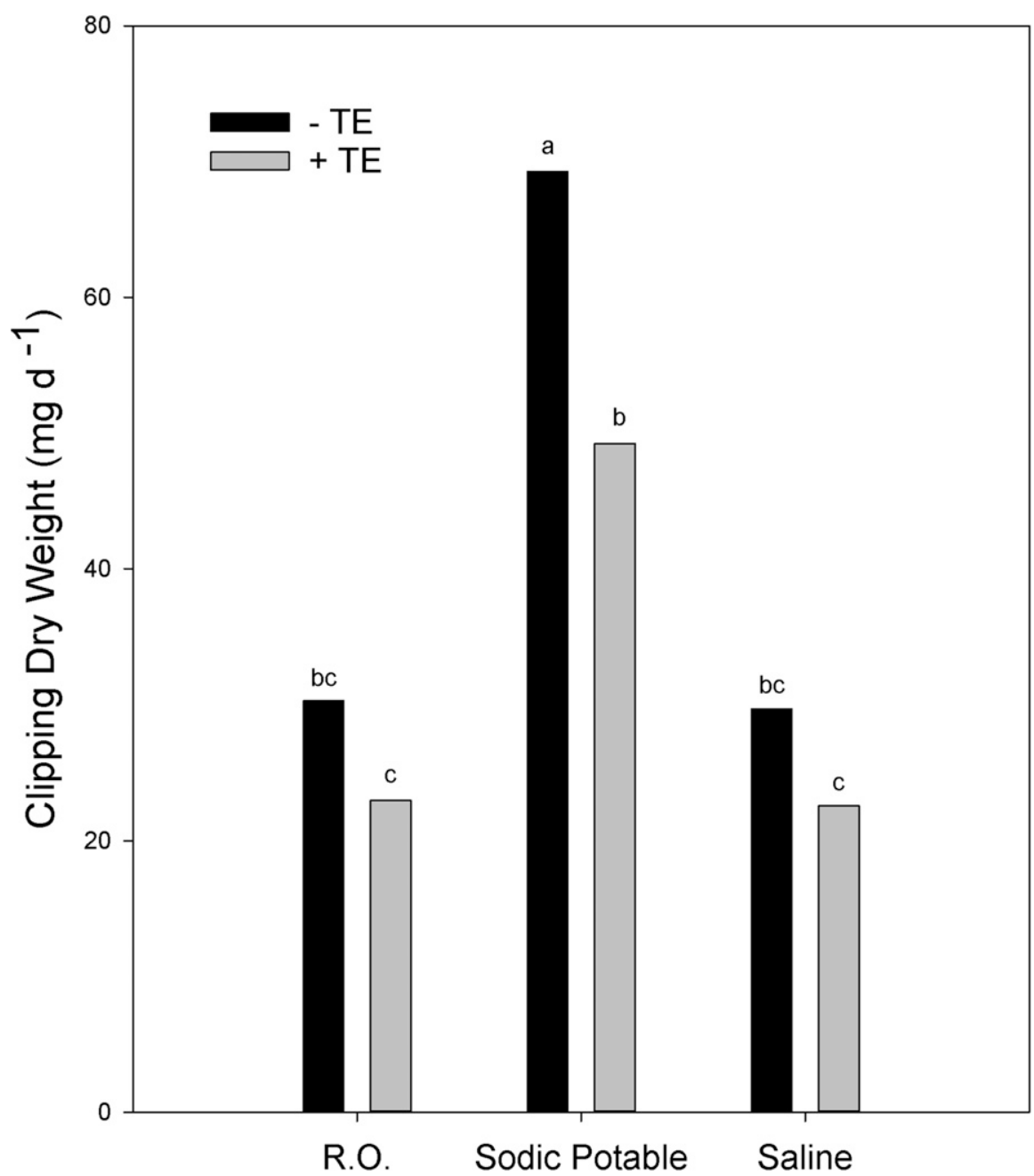

Fig. 6. Grass clipping dry weights from Study 2 as affected by trinexapac-ethyl (TE). Bars with the same letter are not significantly different based on Fishers least significant difference at $P \leq 0.05$. $\mathrm{RO}=$ reverse osmosis

end of the study. Within all water sources, plants receiving TE generally possessed similar or higher quality compared with their-TE counterparts (data not shown).

When irrigation stress became apparent, TE-treated bermudagrass maintained higher turf quality levels than did the untreated at the deficit stress level. These results are consistent with Jiang and Fry (1998) and McCann and Huang (2007) that TE can enhance coolseason turf quality during periods of water deficit. McCann and Huang found that plants pretreated with TE maintained higher quality compared with untreated plants up to $21 \mathrm{~d}$ after onset of drought. Unlike McCann and Huang (2007) who pretreated bentgrass plants with TE every $14 \mathrm{~d}$ for $42 \mathrm{~d}$ before exposing them to drought, bermudagrass in this study was treated every 3 weeks beginning with the onset of water stress. The theory behind this method was that 'Tifway' bermudagrass was found to metabolize TE within 4-6 weeks (Fagerness et al., 2004; Fagerness and Yelverton, 2000; McCullough et al., 2007), so reapplying TE before the plants could fully metabolize the TE, might potentially provide further benefit to turf in the full ET replacement $\left(1.0 \times \mathrm{ET}_{\mathrm{a}}\right)$ treatment because of the greater total amounts of water and salts applied.

While the saline irrigation treatment caused the greatest increases in EC within the $1.0 \times \mathrm{ET}_{\mathrm{a}}$ irrigation treatment, the only significant differences in visual quality were observed at three dates during study 2 . One possible reason for this is that salinity stress was caused by salt accumulation within the saline treatment of the full replacement lysimeters during summer as a result of replacing higher water volumes. We did not find more significant differences within the water quality treatments due to EC levels not reaching damaging levels during the 10-week studies. Bermudagrass has been shown to possess good tolerance to soil salinity over $10 \mathrm{dS} \cdot \mathrm{m}^{-1}$ (Harivandi et al., 1992), but in our studies soil salinity levels did not exceed $3 \mathrm{dS} \cdot \mathrm{m}^{-1}$.

Effects of irrigation and TE on shoot growth. There was a main effect of TE on bermudagrass clipping dry weights in both studies (Table 2). In spring, clippings from TE-treated plants were reduced by $60 \%$ relative to untreated plants (Fig. 5). In summer, clippings were reduced by only $25 \%$ from TE treatment (data not shown). The greater relative growth suppression observed during the spring compared with the summer suggests that more rapid metabolism of TE may have occurred with the longer days and higher incident radiation of summer. Decreased summer efficacy of TE has been previously reported in multiple species and is considered a result of more rapid metabolism in the plant (Beasley and Branham, 2007; Kreuser and Soldat, 2011; Lickfeldt et al., 2001; Wherley and Sinclair, 2009). Furthermore, our data showed no significant $\mathrm{TE} \times$ irrigation level interaction in either study, suggesting that relative levels of growth suppression provided by TE were similar between full- and deficit-irrigated treatments.

In the summer study, there was also a water source $\times$ TE interaction detected (Table 2). As such, although TE reduced clippings across all treatments, these differences were only significant under sodic potable irrigation (Fig. 6). Also, more than double the amount of shoot growth occurred in sodic-irrigated turf as compared with saline or RO water sources (Fig. 6). This response is consistent with the apparent $\mathrm{ET}_{\mathrm{a}}$ differences caused by the differing water sources. Carbon fixation and plant biomass accumulation have been shown to be intimately linked to transpiration (Sinclair et al., 1984).

Finally, a four-way date $\times$ source $\times$ level $\times$ TE interaction for clipping dry weights was detected for study 2 . While somewhat complex in nature, this interaction appears to have been driven primarily the differing amounts of irrigation applied to achieve ET replacement in each of the water sources and resulting impacts on growth. While clipping growth was constant or slightly decreasing across the 10 weeks for plants grown in saline 


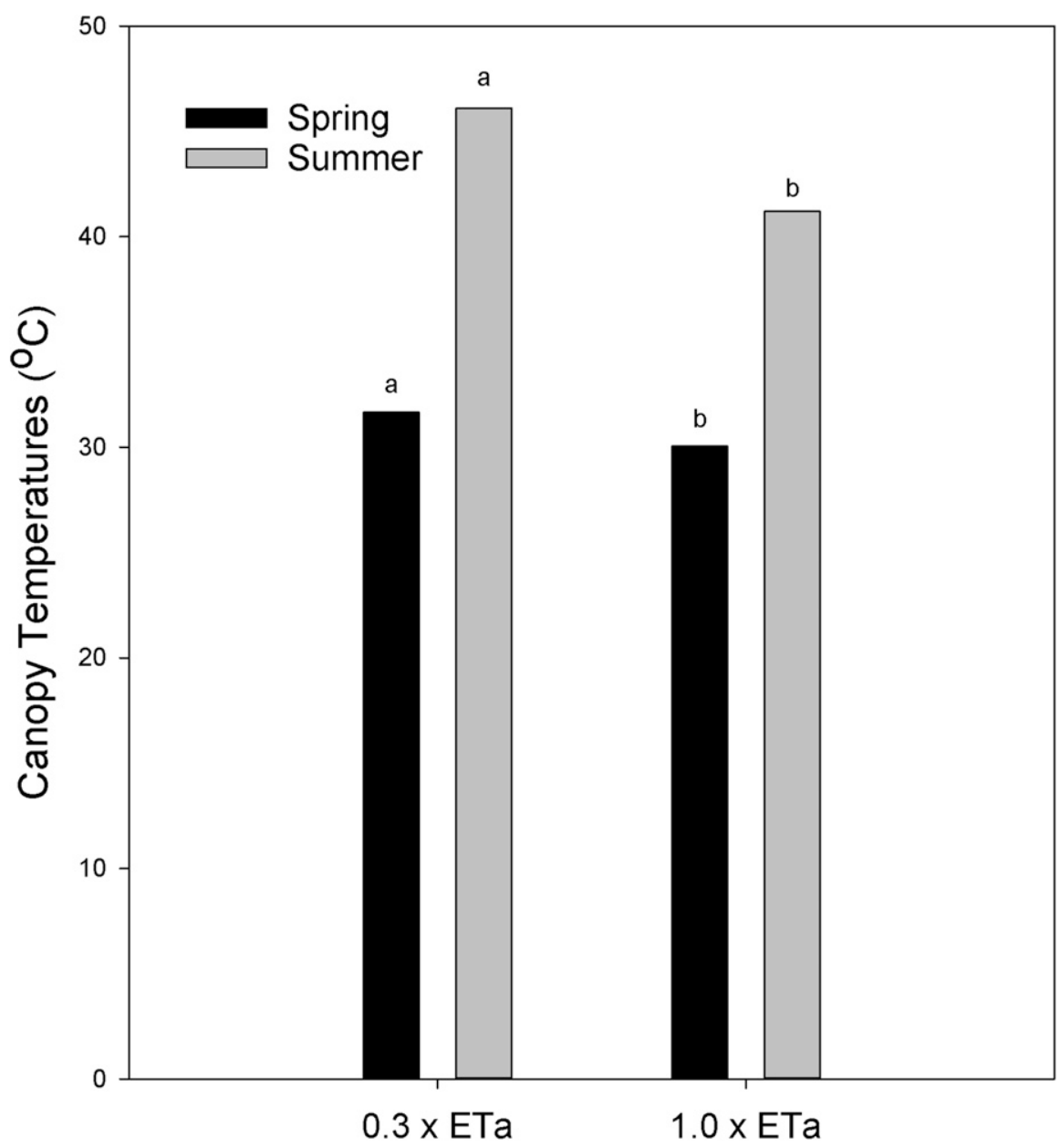

Fig. 7. Canopy temperatures as affected by irrigation level during spring and summer studies. Data were pooled across trinexapac-ethyl (TE) levels and water sources. Within each season, bars with the same letter are not significantly different based on Tukey's honestly significant difference at $P \leq 0.05$.

and RO water sources, levels of growth in sodic potable irrigation were nearly two to three times greater than their RO or saline counterparts for many dates. TE treatment generally led to significant growth reductions within each water source and date, but a substantial rebound effect in growth was observed during the final week within the sodic potable +TE treatment. Incidently, this rebound was not observed in other TE-treated plants in other water sources.

Treatment effects on canopy temperatures. Within both studies, higher canopy temperatures were also observed at lower irrigation levels. Canopy temperatures in the summer study were $10-15{ }^{\circ} \mathrm{C}$ higher than corresponding treatments in spring (Fig. 7). In addition, there was a date $\times$ source $\times$ level interaction for both studies. As such, the highest canopy temperatures were noted in the deficit stress treatment irrigated with RO water (data not shown), which again was likely related to the relatively lower amounts of irrigation applied to these treatments, relative to the other two irrigation water sources. This was also the same treatment that had the poorest visual quality (Fig. 2). In the full irrigation treatment, the RO and sodic water treatments had the lowest were observed within all deficit irrigation treatments, regardless of water chemistry. These results suggest that trinexapac-ethyl may offer short-term mitigation of drought stress under deficit irrigation. They also highlight the need for further research addressing irrigation water-quality effects on turf ET and deficit irrigation responses under field conditions.

\section{Literature Cited}

Alhendawi, R.A., V. Romheld, E.A. Kirkby, and H. Marschner. 2008. Influence of increasing bicarbonate concentrations on plant growth, organic acid accumulation in roots and iron uptake by barley, sorghum, and maize. J. Plant Nutr. 20(12):1731-1753.

Asano, T., R.G. Smith, and G. Tchobanoglous. 1984. Municipal wastewater: Treatment and reclaimed water characteristics, p. 2:1-2:26. In: G.S. Pettygrove and T. Asano (eds.). Irrigation with reclaimed municipal wastewater: A guidance manual. Report No. 84-1 wr. Calif. State Water Resources Control Board, Sacramento, CA.

Beasley, J.S. and B.E. Branham. 2007. Trinexapacethyl and paclobutrazol affect Kentucky bluegrass single-leaf carbon exchange rates and plant growth. Crop Sci. 47(1):132-138.

Ben-Gal, A., E. Ityel, L. Dudley, S. Cohen, U. Yermiyahu, E. Presnov, L. Zigmond, and U. Shani. 2008. Effect of irrigation water salinity on transpiration and on leaching requirements: A case study for bell peppers. Agr. Water Mgt. 95:587-597.

Bernstein, L. 1975. Effects of salinity and sodicity on plant growth. Annu. Rev. Phytopathol. 13:295-312.

Brown, P. and D. Kopec. 2000. Converting reference evapotranspiration into turf water use. Univ. of AZ Coop. Extension Publ. AZ1195, Tucson, AZ.

Duble, R.L. 2006. Water management on turfgrasses. 10 Jan. 2015. <http://plantanswers. tamu.edu/turf/publications/water.html $>$.

canopy temperatures and corresponded to the treatments with highest visual quality ratings (Fig. 2).

\section{Conclusions}

As turf managers increasingly cope with reductions in irrigation water quality and allocation levels, it is important to examine the effects of cultural factors on turf performance under these conditions. Previous research has demonstrated that warm-season grasses are wellsuited for deficit irrigation; however, little is known about the extent to which water quality or growth regulators may affect this response. This research evaluated the effects of irrigation water quality and growth regulator on bermudagrass response to deficit irrigation. The results indicated that sodic irrigation significantly increased ET rates and shoot growth of bermudagrass under full irrigation levels, compared with turf receiving RO or saline irrigation water. Furthermore, TE application improved turfgrass quality and/or delayed firing under soil moisture stress because of deficit irrigation in both studies, with the greatest benefit noted under the less intense conditions of the spring experiment. Elevated canopy temperatures

Fagerness, M.J., D.C. Bowman, F.H. Yelverton, and T.W. Rufty, Jr. 2004. Nitrogen use in Tifway bermudagrass, as affected by trinexapac-ethyl. Crop Sci. 44:595-599.

Fagerness, M.J. and F.H. Yelverton. 2000. Tissue production and quality of 'Tifway' bermudagrass as affected by seasonal application patterns of trinexapac-ethyl. Crop Sci. 40:493-497.

Feldhake, C.M., R.E. Danielson, and J.D. Butler. 1984. Turfgrass evapotranspiration. II. Responses to deficit irrigation. Agron. J. 76: 85-89.

Fry, J.D. and J.D. Butler. 1989. Responses of tall and hard fescue to deficit irrigation. Crop Sci. 29:1536-1541.

Fu, J., J. Fry, and B. Huang. 2004. Minimum water requirements of four turfgrasses in the transition zone. HortScience 39:1740-1744.

Harivandi, M.A., J.D. Butler, and W. Lin. 1992 Salinity in turfgrass culture, p. 207-230. In: D.V. Waddington, R.N. Carrow, and R.C. Shearman (eds.). Turfgrass. Monograph No. 32. American Society of Agronomy, Madison, WI.

Huang, B. and J. Fry. 1999. Turfgrass evapotranspiration, p. 317-334. In: M.B. Kirkham (ed.) Water use in crop production. Food Products Press, New York, NY.

Jiang, H. and J. Fry. 1998. Drought responses of perennial ryegrass treated with plant growth regulators. HortScience 33:270-273. 
Johnston, M., C.P.L. Grof, and P.F. Brownell. 1988. The effect of sodium nutrition on the pool sizes of intermediates of the C4 photosynthetic pathway. Austral. J. Plant Physiol. 15: 749-760.

King, R.W., C. Blundell, L.T. Evans, L.N. Mander, and J.T. Wood. 1997. Modified gibberellins retard growth of cool-season turfgrasses. Crop Sci. 37:1878-1883.

Kreuser, W.C. and D.J. Soldat. 2011. A growing degree day model to schedule trinexapac-ethyl applications on Agrostis stolonifera golf putting greens. Crop Sci. 51:2228-2236.

Lickfeldt, D.W., D.S. Gardner, B.E. Branham, and T.B. Voight. 2001. Implications of repeated trinexapac-ethyl applications on Kentucky bluegrass. Crop Sci. 93(5):1164-1168.

Marcum, K.B. 2006. Use of saline and nonpotable water in the turfgrass industry: Constraints and developments. Agr. Water Mgt. 80:132-146.

Marcum, K.B. and M. Pessarakli. 2006. Salinity tolerance and salt gland excretion efficiency of bermudagrass turf cultivars. Crop Sci. 46:2571-2574.

McCann, S.E. and B. Huang. 2007. Effects of trinexapac-ethyl foliar application on creeping bentgrass responses to combined drought and heat stress. Crop Sci. 47:2121-2128.

McCullough, P.E., H. Liu, L.B. McCarty, and J.E. Toler. 2007. Trinexapac-ethyl application regimens influence growth, quality, and performance of bermudagrass and creeping bentgrass putting greens. Crop Sci. 47:2138-2144.

McFarland, M.L., R.G. Lemon, and C.R. Stichler. 2002. Irrigation water quality. Texas A\&M AgriLife Extension Publ. L-5417, 3/02. 4 pp. 2 July 2015. < http://gillespie.agrilife.org/files/ 2013/02/Irrigation-Water-Quality.pdf $>$.

Pierce, R.C., Y. Li, and L.P. Bush. 1999. Calcium and bicarbonate effects on the growth and nutrient uptake of burley tobacco seedlings: Hydroponic culture. J. Plant Nutr. 27(7):10691078.

Qian, Y. and M. Engelke. 1999. Performance of five turfgrasses under linear gradient irrigation. HortScience 34:893-896.

Sinclair, T.R., C.B. Tanner, and J.M. Bennett 1984. Water-use efficiency in crop production. Bioscience 34(1):36-40.

Stolwijk, J.A. and K.V. Thimann. 1957. On the uptake of carbon dioxide and carbonate by roots, and its influence on plant growth. Plant Physiol. 32(6):513-520.
Taiz, L. and E. Zeiger. 1998. Mineral nutrition. Plant Physiology. Sinauer Associates Publishers, Sunderland, MA.

Throssell, C.S., G.T. Lyman, M.E. Johnson, G.A. Stacey, and C.D. Brown. 2009. Golf course environmental profile measures water use, source, cost, quality, management and conservation strategies. Appl. Turfgrass Sci. doi:10.1094/ATS-2009-0129-01-RS.

Turgeon, A.J. 2002. Turfgrass management.Prentice Hall, Upper Saddle River, NJ.

Wherley, B. 2011. Turfgrass growth, quality, and reflective heat load in response to deficit irrigation practices, p. 419-430. In: Leszek Labedzk (ed.). Evapotranspiration. InTech Publishers, Rijeka, Croatia. 10 Jan. 2015. <http://www.intechopen. $\mathrm{com} /$ books/evapotranspiration/turfgrass-growthquality-and-reflective-heat-load-in-response-todeficit-irrigation-practices $>$.

Wherley, B., J. Heitholt, A. Chandra, and P. Skulkaew. 2014. Supplemental irrigation requirements of zoysiagrass and bermudagrass cultivars. Crop Sci. 54:1823-1831.

Wherley, B. and T.R. Sinclair. 2009. Growth and evapotranspiration response of two turfgrass species to nitrogen and trinexapac-ethyl. HortScience 44:2053-2057. 